\title{
HUBUNGAN MENGIKUTI TRY OUT TERHADAP KELULUSAN UJI KOMPETENSI NASIONAL DIII KEPERAWATAN PADA MAHASISWA STIKES DIRGAHAYU SAMARINDA
}

\author{
Agnesia Winda Kurniati Marlin1, Kornelia Mina2 \\ 1,2 Program Studi DIII Keperawatan STIKES Dirgahayu Samarinda \\ Jalan Pasundan Nomor 21 Kelurahan Jawa Kode Pos 75122, telepon (0541)748335 \\ e-mail: agnesiawinda89@gmail.com
}

\begin{abstract}
Capaian pembelajaran menurut Kerangka Kualifikasi Nasional Indonesia KKNI (Perpres no 8/2012) adalah tercapainya kompetensi melalui proses pendidikan yang terstruktur dan mencakup suatu bidang ilmu/keahlian tertentu atau melalui pengalaman kerja. Evaluasi kompetensi ini didapatkan melalui ujian yang disebut dengan Uji Kompetensi Ners Indonesia (UKNI). Mengetahui hubungan MengikutiTry OutTerhadap Kelulusan Uji Kompetensi Nasional DIII Keperawatan Pada Mahasiswa STIKES Dirgahayu Samarinda. Desain penelitian ini adalah deskriptif analitik dengan pendekatan cross sectional. Teknik sampling penelitian ini yaitu total sampling. Analisis penelitian ini menggunakan uji chi-square. Data responden yang mengikuti Try Out UKOM mahasiswa DIII Keperawatan STIKES Dirgahayu Samarinda tahun 2020, dari total 128 responden tahun 2020, terdapat 126 responden yang mengikuti try out Uji Kompetensi dengan persentase $98 \%$, dan 2 responden yang tidak mengikuti try out Uji Kompetensi dengan persentase 2\%. Data Capaian Kelulusan UKOM Nasional mahasiswa DIII Keperawatan STIKES Dirgahayu Samarinda tahun 2020, dari total 128 responden tahun 2020, terdapat 125 responden kompeten (Lulus) UKOM Nasional dengan persentase $98 \%$, dan 3 responden yang tidak kompeten (tidak lulus) UKOM Nasional dengan persentase 2\%. Hasil analisa data menunjukkan tidak ada Hubungan yang signifikan,antara mengikuti try out terhadap Kelulusan UKOM Nasional DIII Keperawatan STIKES Dirgahayu Samarinda
\end{abstract}

Key Words - Try Out UKOM, DIII Keperawatan

\section{PENDAHULUAN}

Perkembangan Masyarakat Ekonomi ASEAN (MEA) mendorong setiap penyelenggara pendidikan mampu menghasilkan lulusan yang siap bekerja dan mempunyai kinerja yang berkualitas dalam layanan kesehatan pada tingkat Nasional, Regional, dan Global.Perkembangan ini menuntut kesiapan perguruan tinggi dalam meningkatkan kualitas lulusan yang mampu bersaing di tingkat ASEAN. Capaian pembelajaran menurut Kerangka Kualifikasi Nasional Indonesia KKNI (Perpres no 8/2012) adalah tercapainya kompetensi melalui proses pendidikan yang terstruktur dan mencakup suatu bidang ilmu/keahlian tertentu atau melalui pengalaman kerja. Evaluasi kompetensi ini didapatkan melalui ujian yang disebut dengan Ujian Kompetensi Ners Indonesia (UKNI). Mahasiswa keperawatan diharapkan siap menghadapi UKNI tersebut dengan dilaksanakannya melalui Try Out Internal Uji Kompetensi (UKOM).

UKNI telah diberlakukan di Indonesia mulai Agustus 2012, dan saat ini masih banyak lulusan Ners yang belum mampu melewati ujian ini. 
Berdasarkan data RISTEKDIKTI tahun 2018, persentase kelulusan peserta UKNI mengalami penurunan yaitu pada tahun 2016 mencapai $47 \%$ dari 24.234 , sedangkan pada tahun 2017 hanya mencapai 39\% dari 53.692. Data persentase kelulusan mahasiswa program studi DIII Keperawatan STIKES Dirgahayu Samarinda yang mengikuti Uji Kompetensi Nasional DIII Keperawatan bahwa cenderung mengalami fluktuatif di empat tahun terakhir yaitu persentase kelulusan tahun 2017 mencapai $97.7 \%$, tahun 2018 mencapai 95.61\%, tahun 2019 mencapai $85 \%$ dan tahun 2020 mencapai 98\%. Data lulusan tersebut masih belum mencapai target Institusi yaitu $98-100 \%$ mahasiwa peserta UKOM lulus terutama pada tahun 2019. Berdasarkan hasil wawancara pada mahasiswa yang tidak lulus UKOM tahun 2019, mereka beranggapan bahwa peralihan metode ujian paper based test saat try out dengan computer based test saat UKOM sehingga mahasiswa mengalami kesulitan untuk menggunakan teknologi, terlalu lama dalam membaca dan menganalisa soal sehingga kehabisan waktu saat menjawab soal, dan kurangnya latihan soal mandiri selama menunggu pelaksanaan UKOM menjadi penyebab tidak lulus UKOM.

Kesiapan yaitu suatu kondisi awal seseorang yang akan menghadapi suatu hal tertentu yang membuatnya siap untuk memberikan respon yang ada pada dirinya dalam mencapai tujuan tertentu (Nurfatonah, 2014). Kesiapan adalah suatu kondisi yang dimiliki baik oleh perorangan maupun suatu badan dalam mepersiapkan diri baik secara mental, maupun fisik untuk mencapai yang dikehendaki (Astiwi, 2012). Menurut Soemanto (2012) Readiness sebagai kesiapan atau kesediaan seseorang untuk berbuat sesuatu.Ujian adalah suatu kegiatan yang dilakukan untuk menilai sesuatu yang dilaksanakan pada akhir waktu pembelajaran. Ujian dilaksanakan untuk menilai kemampuan hasil belajar selama proses pembelajaran. Ujian kompetensi adalah suatu proses untuk mengukurpengetahuan, keterampilan, dan sikap sesuai dengan standar profesi yang berguna sebagai jaminan bahwa mampu melaksanakan peran profesi secara aman dan efektif kepada masyarakat (AIPNI, 2018).

Try out adalah tahapan gladi bersih menjelang pelaksanaan Ujian yang sesungguhnya. Ujian try out pada hakikatnya merupakan evaluasi hasil belajar yang dilaksanakan oleh lembaga pendidikan sebelum menghadapi ujian yang sesungghunya. Try out digunakan untuk menguji kesiapan peserta didik dalam menghadapi ujian (Sukismo, 2014).Dapat disimpulkan bahwa kesiapan ujian adalah suatu kemampuan yang dimiliki sesorang dalam mepersiapkan diri menghadapi ujian untuk mendapatkan nilai terhadap hasil kemampuan selama proses pembelajaran. Indicator dalam pencapaian hasil ujian tersebut antara lain kondisi fisik, mental, dan emosional. Seseorang dapat memperoleh hasil yang baik apabila memperhatikan pengetahuan, keterampilan, dan kemampuan tersebut. Agenda rutin STIKES Dirgahayu Samarinda dalam mempersiapkan mahasiswa menghadapi UKNI adalah dengan mengikutsertakan mahasiswa semester V sampai VI dalam Try Out Ukom yang dilaksanakan oleh AIPVIKI Regional dan Subregional 1-4 kali dalam setahun yang bertujuan agar mahasiswa mencapai keberhasilan dalam UKNI. Mahasiswa yang tidak lulus pada try out akan mendapat bimbingan khusus oleh tim dosen agar mahasiswa dapat mengetahui kesalahan dalam menjawab soal, sehingga saat 
pelaksanaan UKNI mahasiswa dapat mengerjakan soal-soal dnegan benar.

\section{METODE}

Penelitian ini menggunakan data sekunder dari data bidang akademik (admin UKOM) STIKES Dirgahayu Samarinda. Desain penelitian ini adalah deskriptif analitik dengan pendekatan cross sectional, yaitu dengan cara pengumpulan data sekaligus pada satu waktu dengan tujuan untuk mengetahui hubungan korelasi antar variable. Peneliti merencanakan mengambil data sekunder hasil try out dan hasil UKOM mahasiswa keperawatan tahun 2020 di STIKES Dirgahayu Samarinda. Populasi dalam penelitian ini adalah mahasiswa keperawatan di STIKES Dirgahayu Samarinda tahun 2020 sebanyak 128 responden.

Sampel yang akan digunakan dalam penelitian ini adalah seluruh mahasiswa keperawatan tingkat III di STIKES Dirgahayu Samarinda yang mengikuti Try Out dan Uji Kompetensi Nasional Perawat Indonesia tahun 2020. Teknik pengambilan sampel (sampling) penelitian ini dengan teknik total sampling dalam hal ini penetapan sampel yaitu seluruh total populasi berdasarkan kriteria inklusi.

Kriteria Inklusi: Mahasiswa tingkat III Keperawatan STIKES Dirgahayu Samarinda tahun 2020 yang mengikuti try out, Mahasiswa tingkat III Keperawatan STIKES Dirgahayu Samarinda tahun 2020 yang tidak mengikuti try out,dan Mahasiswa tingkat III Keperawatan STIKES Dirgahayu Samarinda tahun 2020 yang mengikuti Uji Kompetensi Nasional Perawat Indonesia tahun 2020. Kriteria Eksklusi: Retaker STIKES Dirgahayu Samarinda tahun 2020 yang tidak mengikuti try out tetapi mengikuti Uji Kompetensi Nasional Perawat Indonesia tahun 2019 dan tahun 2020.
HASIL

Tabel 1: Data responden yang mengikuti Try Out UKOM mahasiswa DIII Keperawatan STIKES Dirgahayu Samarinda tahun 2020.

\begin{tabular}{cccc}
\hline $\mathrm{N}$ & Mengikut & Frekuens & Persentas \\
$\mathrm{o}$ & $\mathrm{i}$ Try Out & $\mathrm{i}$ & $\mathrm{e}(\%)$ \\
\hline 1 & Ya & 126 & $98 \%$ \\
2 & Tidak & 2 & $2 \%$ \\
\hline
\end{tabular}

Berdasarkan tabel diatas menunjukan bahwa dari total 128responden tahun 2020, terdapat126 responden yang mengikuti try out $\mathrm{Uji}$ Kompetensidengan persentase $98 \%$, dan 2 responden yang tidak mengikuti try out Uji Kompetensidengan persentase $2 \%$.

Tabel 2: Capaian Kelulusan UKOM Nasional mahasiswa DIII Keperawatan STIKES Dirgahayu Samarinda tahun 2020.

\begin{tabular}{cccc}
\hline No & $\begin{array}{c}\text { Kelulusan } \\
\text { UKOM }\end{array}$ & Frekuensi & $\begin{array}{c}\text { Presentase } \\
(\%)\end{array}$ \\
\hline 1 & Kompeten & 125 & $98 \%$ \\
2 & Tidak & 3 & $2 \%$ \\
& Kompeten & & \\
\hline
\end{tabular}

Berdasarkan tabel diatas menunjukan bahwa dari total 128 responden tahun 2020, terdapat 125 responden kompeten (Lulus)UKOM Nasional dengan persentase $98 \%$, dan 3 responden yang tidak kompeten (tidak lulus) UKOM Nasional dengan persentase $2 \%$. 
Tabel 3: Hubungan mengikuti try out Terhadap Kelulusan UKOM Nasional DIII Keperawatan STIKES Dirgahayu

Samarinda.

\begin{tabular}{|c|c|c|c|c|c|c|}
\hline \multirow[t]{2}{*}{ No } & \multirow{2}{*}{$\begin{array}{c}\text { Mengikuti } \\
\text { Try Out } \\
\text { UKOM }\end{array}$} & \multicolumn{2}{|c|}{$\begin{array}{c}\text { Kelulusan } \\
\text { UKOM }\end{array}$} & \multicolumn{2}{|l|}{ Jumlah } & \multirow[t]{2}{*}{$\begin{array}{c}\mathrm{P} \\
\text { value }\end{array}$} \\
\hline & & Lulus & $\%$ & $\begin{array}{l}\text { Tidak } \\
\text { Lulus }\end{array}$ & $\mathrm{N}$ & \\
\hline 1 & $\mathrm{Ya}$ & 123 & $96 \%$ & 3 & 126 & 0825 \\
\hline 2 & Tidak & 2 & $2 \%$ & - & 2 & $0,8<5$ \\
\hline 3 & \multicolumn{3}{|c|}{ Total Responden } & 128 & & \\
\hline
\end{tabular}

Berdasarkan hasil analisis Hubungan mengikuti try out terhadap Kelulusan UKOM Nasional DIII Keperawatan STIKES Dirgahayu Samarinda, menggunakan uji statistic chi-squaredengan derajat kemaknaan $95 \%, \alpha$ sebesar 0,05 . Diperoleh nilai $\mathrm{P}$ value 0,825 lebih besar dari nilai $\alpha(p$ value $\geq 0,05$ ) sehingga $\mathrm{H} 0$ diterima, berarti tidak ada hubungan yang signifikan antara mengikuti try out terhadap Kelulusan UKOM Nasional DIII Keperawatan STIKES Dirgahayu Samarinda.

\section{PEMBAHASAN}

Berdasarkan penelitian yang telah dilakukan oleh (Othman, Hartina, dan Nurdin 2017), ada beberapa faktor yang dapat mempengaruhi tingkat kelulusan dalam mengikuti Uji Kompetensi (UKNI). Faktor-faktor yang memiliki pengaruh sangat signifikan terhadap mahasiswa untuk lulus Uji Kompetensi ialah faktor internal meliputi: intelegensia, prestasi akademik (IPK), motivasi belajar, kesiapan ujian, serta kondisi fisik dan psikis mahasiswa. Sedangkan faktor eksternal meliputi; peran institusi, dan dukungan keluarga.
Berdasarkan data diatas dapat disimpulkan bahwa mengikuti try out UKOM merupakan hal yang penting dan wajib dikuti oleh mahasiswa sebelum pelaksanaan UKOM Nasional agar mahasiswa memiliki pengalaman serta gambaran dalam menjawab soalsoal UKOM. Tetapi tidak dapat dipungkiri bahwa ada faktor internal dan eksternal lainnya yang juga sangat berpengaruh terhadap kelulusan UKOM sehingga kedepannya perlu diteliti lebih lanjut.

\section{KESIMPULAN DAN SARAN Kesimpulan}

Responden berjumlah 128orang. 126 responden dengan persentasi 98\% mengikutitry out UKOM, dan 2 responden dengan persentasi $2 \%$ yang tidak mengikuti try out UKOM. Responden berjumlah 128 orang. 125 responden dengan persentasi $98 \%$ yang Kompeten (Lulus) UKOM Nasional, dan 3 responden dengan persentasi $2 \%$ yang Tidak Kompeten (tidak lulus) UKOM Nasional. Berdasarkan hasil analisis Hubungan mengikuti try out terhadap Kelulusan UKOM Nasional DIII Keperawatan STIKES Dirgahayu Samarinda, menggunakan uji statistic chi-square diperoleh nilai $\mathrm{P}$ value 0,825 lebih besar dari nilai $\alpha$ ( $p$ value $\geq 0,05)$ sehingga $\mathrm{H} 0$ diterima, berarti tidak ada hubungan yang signifikan antara mengikuti try out terhadap Kelulusan UKOM Nasional DIII Keperawatan STIKES Dirgahayu Samarinda.

\section{Saran}

Bagi Pendidik dan Institusi STIKES Dirgahayu Samarinda.

Diharapkan dapat digunakan
sebagai bahan
pembelajaran dan
Dosen untuategi bagi


mahasiswa dalam menghadapi Uji Kompetensi Nasional Keperawatan.

2. Perlu dilakukan penelitian lanjutan mengenai Faktor-faktor internal dan eksternal yang mempengaruhi kelulusan Uji Kompetensi Nasional selain try out diantaranya: intelegensia, prestasi akademik (IPK), motivasi belajar, kesiapan ujian, kondisi fisik dan psikis mahasiswa, peran institusi, dan dukungan keluarga.

\section{DAFTAR PUSTAKA}

Abdillah, A. (2016) "Analisis FactorFaktor Yang Mempengaruhi Kelulusan Uji Kompetensi Ners Indonesia," Jurnal Penelitian Administrasi Publik, 2(2).Hal.373-380.

AIPNI (2016) Kurikulum Inti Pendidikan Ners Indonesia 2015.Asosiasi Institusi Pendidikan Ners Indonesia.

DIKTI (2014) Peningkatan Kompetensi lulusan Pendidikan Tinggi Kesehatan Melalui Uji Kompetensi. Jakarta.

Kholifah, S (2016), Hambatan Lulusan Ners dalam Menghadapi Uji Kompetensi Ners Indonesia, "The Indonesian Journal Health Science, 7”. 